\title{
RAM - Revista de Administração Mackenzie: sua trajetória e desafios
}

SILVIO POPADIUK ${ }^{1}$

VITÓRIA BATISTA SANTOS SILVA'

${ }^{1}$ Universidade Presbiteriana Mackenzie (UPM) / Centro de CIÊnCIAS Sociais e Aplicadas (CCSA), SÃo PaUlo - SP, Brasil

\section{Resumo}

Este artigo trata do histórico da RAM - Revista de Administração Mackenzie, desde sua fundação em 2000 até 2018 , abordando aspectos relativos à evolução do periódico, fazendo menção aos que mais contribuíram para a consolidação dessa trajetória, e também construindo um perfil do que é esperado pela revista para novas submissões.

Palavras-chave: RAM. Administração de Empresas. Periódicos. Mackenzie. Scielo.

\section{RAM - Revista de Administração Mackenzie: its history and challenges}

\section{Abstract}

This article approaches the history of RAM - Revista de Administração Mackenzie, since the journal's foundation in 2000 until 2018 . It analyzes aspects related to the evolution of the journal, mentioning those who contributed to the consolidation of this journey, and building a profile of what is expected from new submissions.

Keywords: RAM. Business Administration. Journals. Mackenzie. Scielo.

\section{RAM - Revista de Administração Mackenzie: su trayectoria y retos}

\section{Resumen}

En este artículo se hace una reseña histórica de la RAM - Revista de Administração Mackenzie, desde su fundación en el año 2000 hasta el año 2018. Se analizan aspectos relativos a la evolución del periódico, haciendo mención a los que más contribuyeron a la consolidación de esta trayectoria, y también perfilando lo que la revista espera de las nuevas remisiones de artículos.

Palabras clave: RAM. Administración de Empresas. Revistas. Mackenzie. Scielo. 


\section{INTRODUÇÃO}

A RAM - Revista de Administração Mackenzie foi criada no ano 2000, após a reestruturação do Programa de Pós-Graduação em Administração de Empresas da Universidade Presbiteriana Mackenzie (PPGA/UPM). Um ano antes, o então editor-chefe do periódico, e atual professor da UPM, professor Moisés Ari Zilber, em conversa com o reitor da instituição na época, sugeriu o nome de Revista de Administração Mackenzie, pois sua forma abreviada remeteria à ideia de memória RAM.

\section{Seções da RAM}

A revista se divide em 3 seções temáticas. A primeira delas é a de Gestão Humana e Social nas Organizações (GHS), que contempla estudos relacionados a questões humanas e sociais, diversidade, aprendizagem e, também, discussões culturais. Já a seção de Recursos e Desenvolvimento Empresarial (RDE) engloba artigos que tratam de desenvolvimento nas organizações, como inovações, modelos de negócios e de gestão organizacional, estudos sobre concorrência, conhecimento organizacional, relações dinâmicas e redes organizacionais, entre outros. A última seção é a de Finanças Estratégicas (FIN), que discute geração de valor, captação e aplicação de recursos, sejam eles financeiros ou não financeiros, fusões e aquisições, eficiência de mercado, finanças governamentais, estrutura de capital e demais questões relacionadas.

\section{Histórico e assuntos abordados}

Desde o início, o objetivo da RAM foi contribuir com o campo da gestão e da inovação de negócios, tornando o conhecimento científico compreensível tanto por docentes quanto por profissionais de grandes empresas e executivos, entre outros, que configuram o público-alvo da revista. A primeira edição da RAM foi publicada com 7 artigos, escritos totalmente ou em parceria com professores da UPM. Em 2001 foi publicada a segunda edição da revista, também com 7 artigos, sendo 1 de autoria do renomado economista Antônio Delfim Netto, a respeito da Área de Livre Comércio das Américas (Alca) (DELFIM NETO, 2001), assunto muito comentado na época em termos internacionais.

A partir de 2002, a RAM passou a contar com 2 edições semestrais, sendo que a segunda delas já contava então com 8 artigos. Alguns anos depois, em 2005, a revista conseguiu publicar 3 edições anuais e em 2006 houve 4 edições anuais, que contavam com 6 artigos cada.

Foi em 2008 que o professor Moisés Ari Zilber deixou a posição de editor-chefe da RAM e o professor Walter Bataglia assumiu o cargo. Nesse mesmo ano foi publicada a primeira edição especial da revista, com a temática Metodologia de Pesquisa. Ainda em 2008 foi publicada mais uma edição especial, abordando questões relacionadas ao empreendedorismo, que haviam sido apresentados no V EGEPE - Encontro de Estudos sobre Empreendedorismo e Gestão de Pequenas Empresas, ocorrido no mesmo ano.

No ano seguinte, foram publicadas 6 edições anuais, com 7 artigos cada, e já com as seções - GHS, RDE ou FIN - definidas para os artigos. Das 6 edições anuais, 2 foram especiais, uma delas abordando a temática de valores e a outra com artigos em comemoração ao Jubileu de Ouro de Modigliani \& Miller, que seriam os 50 anos da contribuição dos economistas Franco Modigliani e Merton Miller com um teorema que leva seus respectivos nomes, e foi crucial para o desenvolvimento da teoria das finanças corporativas (RIBEIRO, 2009). A partir de 2012, a RAM passou a contar com 8 artigos por edição.

A RAM continuou se expandindo nos anos seguintes, com edições especiais discutindo temas como inclusão nas organizações, diversidade organizacional, desenvolvimento sustentável, estratégias organizacionais, valores humanos e gestão, o campo de ensino e de pesquisa na área de administração, inovação, vida laboral, entre outros - todos assuntos de extrema relevância para o desenvolvimento científico da área de administração de empresas.

A partir da segunda metade de 2014, o professor Walter Bataglia deixou o cargo de editor-chefe da revista e quem assumiu foi o professor Silvio Popadiuk, que permanece até hoje como editor-chefe da revista. Foi em 2016 que a RAM começou a publicar os textos dos artigos em inglês. Atualmente, a submissão pode ser feita em português, espanhol ou inglês. Entretanto, os autores têm a responsabilidade de traduzi-los para a língua inglesa, caso o artigo seja aprovado. Além disso, a partir de 2016, a RAM passou a adotar um nome fantasia em Inglês: Mackenzie Management Review - MMR, visando a facilitar sua divulgação internacional ao ser acessada por mecanismos de busca na internet. Contudo, o nome oficial não foi alterado, devido às implicações formais e técnicas associadas às bases de indexação.

Em 2018, a RAM voltou a ter 6 artigos por edição, com 6 edições anuais. 


\section{Indexadores}

A RAM é indexada por bases importantes do meio científico, dentre elas a SciELO, RedAlyc, EBSCO, ICAP, SPELL, PROQUEST, OAI Harvester, Gale Cengage Learning, CLASE, DOAJ etc. Em julho de 2018 a RAM foi aceita para ser indexada na SCOPUS, o que deverá proporcionar maior visibilidade internacional. Atualmente, a revista é classificada como B1 pelo índice Qualis Capes.

\section{Mudanças que agilizaram o processo}

A partir de 2016, a revista também mudou sua plataforma de submissão. Até então, todas as submissões eram feitas via plataforma SEER - Sistema Eletrônico de Editoração de Revistas. Após a indexação da RAM pela SciELO, a revista tem todas as suas submissões recebidas via plataforma ScholarOne Manuscripts, um sistema que visa a agilizar o processo de avaliação dos artigos e também é utilizado por diversos periódicos reconhecidos no meio internacional. O acesso à plataforma ScholarOne para submeter artigos para a RAM se dá por meio do link <https://mc04.manuscriptcentral.com/ram-scielo>.

Quando de sua fundação, a RAM tinha edições eletrônicas e impressas, mas hoje as edições são apenas eletrônicas e ficam disponíveis no site da SciELO, podendo ser acessadas por meio do link <http://www.scielo.br/ram>, a partir das edições de 2008. As edições anteriores estão disponíveis na plataforma antiga da revista. Dentre as modificações pelas quais o periódico passou, vale a pena citar, ainda, a adoção do fluxo contínuo de publicação a partir de 2018, o que significa que assim que o artigo for aprovado e o processo editorial estiver concluído, ele já pode ser publicado.

No ano de 2015, a RAM também adotou o padrão de Licença CC-BY (Creative Commons - BY), de modo que passou a ser livre o acesso aos conteúdos publicados pela revista, bem como a veiculação das informações, inclusive para fins comerciais, desde que devidamente citadas as fontes.

\section{Submissão e avaliação}

Para o artigo ser aceito, ele precisa ter boa apresentação geral, possuir relevância para o meio científico, trazendo contribuições teóricas ou empíricas para a área, e adequar-se à política editorial da RAM. O artigo precisa ter em sua composição uma introdução - que explicite o problema de pesquisa e os objetivos gerais e específicos do artigo -, uma seção de fundamentação teórica, que explore a literatura já existente a respeito do que está sendo investigado e contemple os principais estudos já desenvolvidos na área. Precisa, ainda, conter a metodologia, abordando de maneira clara e profunda como pretende ser tratado o problema de pesquisa e a discussão sobre os resultados e, por fim, uma seção de considerações finais e sugestões de pesquisas futuras. Não são aceitos artigos que contenham apenas a revisão da literatura e/ou bibliometria. A RAM não cobra taxas dos autores nem para a submissão nem para a análise do artigo, tampouco cobra pela publicação.

No que diz respeito ao processo de avaliação, utiliza-se o processo conhecido como revisão por pares e "às cegas" (blind review). O número de submissões é limitado a 2 artigos por autor a cada ano. Os arquivos submetidos não devem conter nenhuma informação que permita identificar os autores. As informações são acrescentadas caso o artigo seja aprovado. As figuras, os gráficos e as tabelas devem ser submetidos tanto no próprio corpo do texto quanto separadamente, como documentos suplementares. O número máximo de autores por artigo é 5.

Além disso, já no ato da submissão, exige-se o preenchimento do ORCID do autor correspondente. Esse código é um padrão que visa a conectar pesquisadores e demais profissionais relacionados no mundo todo, por meio de um número de identificação. Após o artigo ser aceito, todos os autores precisam fornecer o código do ORCID, que será publicado junto às demais informações autorais. Para que os autores possam efetuar o cadastro de seu ORCID, basta acessar o link <https:// orcid.org/signin> e preencher as informações que julgar convenientes. O ORCID já vem sendo interpretado como essencial por diversos periódicos de relevância em vários países.

Assim que o artigo é submetido, ele passa por uma análise inicial, que confere se o estudo segue as diretrizes do periódico no que se refere a formatação e número de palavras. Nessa primeira avaliação, o artigo também é submetido ao sistema iThenticate, que fornece a porcentagem de plágio contida nos textos, e ajuda a identificar se os textos foram extraídos de trabalhos acadêmicos ou se já foram apresentados em algum congresso da área.

Também se confere se os autores já submeteram algum artigo no período recente ou se o mesmo artigo já foi submetido à revista, uma vez que 1 artigo não pode ser submetido 2 vezes para a revista, independentemente de haver alteração da seção à qual ele pertence ou das demais informações sobre o arquivo. A RAM tem seus artigos publicados com formatação 
segundo as normas da American Psychological Association (APA), contendo entre 7.600 e 8.400 palavras e 5 palavras-chave, além de seguir uma estrutura de resumo/abstract comum, reproduzida abaixo e disponível no site da SciELO (RAM, 2018a):

Objetivo: consiste na apresentação das intenções a ser atingidas com o trabalho. Como sugestão apresentamos a classificação de Blaikie (2009);

Explorar: apresentar uma descrição inicial ou a compreensão de algum fenômeno;

Descrever: proporcionar um conjunto detalhado de dados ou medidas das características de alguma população (amostra), grupo ou fenômeno, incluindo-se regularidades presentes nos dados;

Explicar: estabelecer os elementos, fatores ou mecanismos que são responsáveis para a produção do estado ou das regularidades do fenômeno estudado;

Compreender: estabelecer as razões inerentes a uma ação social particular, a ocorrência de um evento ou o desenvolvimento de um episódio social;

Prever: utilizar entendimentos estabelecidos ou explicações de um fenômeno para inferir certas resultantes segundo condições particulares;

Modificar: intervir em uma situação social mediante a manipulação de alguns aspectos dela ou para auxiliar os participantes na mudança, preferencialmente com base em compreensão ou explicação pré-estabelecida;

Originalidade/valor: explique porque o artigo deve ser considerado original. Qual lacuna de conhecimento ele preenche? Existem questões não respondidas sobre o tema pesquisado? Apresenta nova abordagem, novo conceito, nova teoria, novo paradigma? Promove mudanças ou avanços no conhecimento em termos de conceitos, relacionamentos, modelos ou teorias? Qual é sua utilidade prática (E daí?). Apresenta tendências que podem contribuir para mudanças organizacionais presentes e futuras?

Design/metodologia/abordagem: descreva sucintamente a abordagem metodológica e as técnicas de pesquisa qualitativa, quantitativa, mista. Estratégia de pesquisa. Técnica de coleta de dados e análise de dados. Se for um texto teórico, explique os procedimentos adotados (revisão sistemática da literatura, bibliometria, meta-análise, proposição de modelo ou teoria etc.).

Resultados: o que os resultados significam (interpretações à luz das teorias relevantes), especialmente no contexto do que já era conhecido sobre o objeto da investigação? As conclusões não devem avançar e ser estendidas além do que é suportado por seus resultados. Quais seriam as aplicações práticas de resultados e quais seriam os próximos passos na pesquisa?

Após a verificação inicial, o artigo é destinado pelo editor-chefe a um editor associado da área - processo conhecido como desk review -, que irá enviar o artigo para 2 avaliadores, que têm o prazo de 21 dias para fornecer uma opinião embasada a respeito dos pontos fracos e fortes do artigo, sugerindo as possíveis modificações que direcionariam o texto à aprovação. Após obter o parecer se o artigo deve ser aceito, rejeitado, ou revisado - opção mais comum, para a primeira versão submetida do artigo, a fim de dar prosseguimento à análise -, caso haja divergências entre as visões dos avaliadores são designados mais avaliadores, até que o editor associado possa tomar a decisão cabível.

Quando se preparam edições especiais, em geral, são convidados professores de prestígio especialistas no tema, que acabam assumindo o papel do editor-chefe ao longo de todo o processo de avaliação dos artigos. Nessas situações, o papel do editor associado - ou editor de seção - desaparece, dando lugar a um pequeno grupo de professores que selecionam os artigos que comporão a edição em questão. Para a última edição especial de 2018 (Edição 19.6) foram convidados 4 professores que selecionaram os melhores textos para inclusão.

Também vale ressaltar que o corpo de avaliadores da revista é composto por pesquisadores e docentes de prestígio da área, contemplando membros de faculdades renomadas de todo o Brasil ou, ainda, de outros países, cada um deles dentro de sua especialidade. Esses pareceristas têm como principal função fornecer suporte ao restante do corpo editorial, fornecendo seus pontos de vista de modo fundamentado. Os avaliadores não recebem nenhuma remuneração pelas análises fornecidas, mas podem solicitar uma declaração de avaliação, caso seja necessário.

Assim que essa parte é finalizada, o editor associado devolve o artigo aos autores, para que sejam realizadas as modificações sugeridas pelos avaliadores. Em um prazo de 21 a 30 dias, dependendo do tipo de revisão solicitada, os autores submetem 
a versão revisada/modificada do artigo via plataforma novamente. Ao receber a versão revisada ("R1") do artigo, a equipe técnica verifica se as diretrizes continuam sendo respeitadas após as alterações realizadas no arquivo. Em seguida, o editorchefe encaminha o artigo novamente ao editor associado, a fim de que ele dê prosseguimento à análise, convidando os avaliadores a verificar se as modificações solicitadas foram atendidas.

Com base nos pareceres dos avaliadores, o editor associado deixa registrada no sistema uma recomendação a respeito de qual deve ser a decisão a ser tomada, bem como os motivos que justificam essa escolha. Se essa resposta for positiva, a decisão de aprovação será tomada pelo editor-chefe. Caso contrário, é possível em alguns casos que seja solicitada uma nova revisão para o artigo, ou então ele também é rejeitado pelo editor-chefe.

A partir do momento que o artigo é aprovado, os autores são comunicados dessa decisão, e têm 15 dias para enviar à equipe técnica da RAM a versão traduzida do artigo - caso ele não tenha sido submetido em inglês - com as demais informações pertinentes. $O$ processo completo, considerando o dia da submissão inicial até a decisão final sobre o artigo, costuma ter a duração de 120 dias. Após a finalização do processo editorial, os autores recebem o aviso de que é preciso enviar o documento assinado de transferência de direitos autorais. A publicação do artigo não pode ocorrer sem que esse documento tenha sido recebido pela equipe administrativa da revista.

A Editora Mackenzie é patrocinadora da revista e, como tal, possui um corpo editorial responsável por gerir os processos seguintes até a publicação final do artigo na página da SciELO, como a revisão do conteúdo, diagramação, entre outros. Todas as atividades no decorrer do processo editorial são pautadas pelo documento de "Boas Práticas da Publicação Científica" divulgada pela Anpad - Associação Nacional de Pós-Graduação e Pesquisa em Administração, cuja versão atualizada pode ser acessada no site da ANPAD (2017).

\section{Estatísticas}

O número de submissões de artigos para a RAM sofreu queda nos últimos anos, em razão das maiores exigências para os artigos aceitos, a exemplo da tradução para o inglês. Até 2016 eram submetidos cerca de 250 artigos por ano. A partir de 2017 houve uma redução da taxa de submissão, em razão de outras exigências da RAM e também devido à necessidade do artigo ser vertido para o idioma inglês, caso fosse aprovado para publicação. Dos artigos submetidos, em geral, a maior parte é direcionada à seção de Gestão Humana e Social. Estima-se que a RAM já tenha publicado, ao longo de quase 20 anos de existência, cerca de 620 artigos. Ressalta-se que cerca de $80 \%$ dos artigos submetidos são rejeitados devido a problemas de formatação, inadequação às políticas da RAM, pequena contribuição acadêmica e prática para a área envolvida, fundamentação teórica desatualizada ou mesmo pouco pertinente ao tema do artigo, procedimentos metodológicos e análises inadequadas, bem como conclusões que não refletem devidamente as proposições ou hipóteses associadas ao estudo desenvolvido.

Os estados brasileiros cujos autores mais submetem artigos à RAM, em geral, são da região Sudeste, mais especificamente São Paulo e Minas Gerais. O Rio Grande do Sul também tem uma participação significativa no total de submissões. A revista também já publicou artigos de autores estrangeiros, de países como Argentina, Chile, Uruguai, Portugal, Estados Unidos da América (EUA), Canadá, Países Baixos etc.

Segundo as estatísticas disponíveis na página da SciELO (RAM, 2018b), o artigo publicado na RAM que mais teve acessos foi o texto da edição 12.3, de 2011, intitulado "Desenvolvimento sustentável, consumo e cidadania: um estudo sobre a (des) articulação da comunicação de organizações da sociedade civil, do estado e das empresas", de autoria de Daniela Viegas da Costa e Armindo dos Santos de Sousa Teodosio (COSTA e TEODOSIO, 2011). O artigo aborda o consumo e o comportamento dos consumidores na atualidade, discutindo os impactos desse comportamento na economia como um todo e compreendendo as políticas que podem ser implementadas em termos de renovação de práticas de consumo.

Com as informações abaixo, pode-se visualizar algumas estatísticas relevantes sobre a RAM, que dizem respeito aos últimos 10 anos da revista:

- A RAM publicou 65 edições nos últimos 10 anos;

- Entre artigos e apresentações, há um total de 569 documentos disponíveis a partir de 2008;

- Nesses documentos, foram citados cerca de 21.100 trabalhos;

- Depois do Brasil, o país que tem mais autores com artigos publicados na RAM são os EUA. 


\section{CONSIDERAÇÕES FINAIS}

Com base nas políticas editoriais e nos procedimentos de análise expostos, a RAM preza pelo desenvolvimento e pela evolução das boas práticas científicas, buscando estudos que tragam contribuições significativas para o campo da administração de empresas, sempre considerando o parâmetro de excelência das atividades acadêmicas.

Vale mencionar, ainda, que a revista zela pelo bom diálogo com seus membros e com os autores, sempre procurando atender às necessidades de cada um deles da melhor forma possível, estando aberta a sugestões, comentários e contribuições para o aprimoramento de suas atividades.

Entende-se que o papel desempenhado pela RAM nesses quase 20 anos de existência tenha contribuído para o processo de geração de conhecimentos associados às áreas de estratégia, gestão humana e social e finanças estratégicas. Como se observa no histórico aqui apresentado, a RAM teve uma evolução elogiável que lhe permite situar-se em patamares superiores de qualidade, sendo um de seus objetivos nos próximos anos ter índices de impacto comparáveis com periódicos internacionais relativos a questões inerentes à gestão estratégica das organizações.

Destaca-se a tradição da academia brasileira ao privilegiar a RAM com sua escolha para a produção científica nacional, como aponta sua posição em sexto lugar entre os periódicos domésticos na área de administração com maior fator de impacto de 2 e 5 anos sem autocitação (a partir de 2016) no SPELL da Anpad que reúne toda a produção em periódicos brasileiros (<http:// www.spell.org.br/>). É uma honra para nós!

\section{AGRADECIMENTOS}

Queremos dividir essa conquista com todos que colaboram ou colaboraram nessa caminhada de quase 20 anos.

Muitos são os que tiveram uma participação ativa nessa jornada. Aqui enumeramos alguns desses agentes.

Em primeiro lugar, o professor Reynaldo Cavalheiro Marcondes, que articulou um novo modelo para o PPGA/UPM e no "kit" do programa ele também incentivou a criação da RAM em 2000, cujos "tracks" são idênticos às 3 linhas do PPGA: Recursos e Desenvolvimento Empresarial; Gestão Humana e Social nas Organizações; e Finanças Estratégicas.

O professor Moisés Ari Zilber foi o primeiro editor-chefe e estruturou as primeiras edições de janeiro de 2000 a abril de 2008. O professor Walter Bataglia deu continuidade à gerência da RAM de maio de 2008 a julho de 2014 e, na sequência, até os dias atuais, a RAM se encontra sob a responsabilidade do professor Silvio Popadiuk.

Muitos foram os editores de seção, editores convidados, participantes do corpo editorial e membros do conselho de política editorial, bem como aproximadamente 200 avaliadores, além dos vários autores que, de alguma forma, contribuíram para essa conquista. É impossível enumerar todos.

Um agradecimento especial deve ser feito às várias assistentes que passaram pela RAM. Sem elas teria sido impossível realizar as várias etapas dos processos de recepção, pré-análise, indicação de editores, contato com autores, documentações, preparação para a edição e muitas outras atividades. Também cabe nosso sincero agradecimento à Editora Mackenzie, que é a responsável por todo o processo de editoração de texto da RAM!

A reitoria e o Centro de Ciências Sociais e Aplicadas (CCSA) da UPM também têm uma participação muito grande nessa conquista, em razão de serem os agentes financiadores das edições da RAM. 


\section{REFERÊNCIAS}

ASSOCIAÇÃO NACIONAL DE PÓS-GRADUAÇÃO E PESQUISA EM ADMINISTRAÇÃO - ANPAD. Boas práticas da publicação científica: manual para autores, revisores, editores e integrantes de corpos editoriais. 2017. Disponível em: <http://www.anpad.org.br/ anpad/ diversos/2017/2017_Boas_Praticas.pdf>. Acesso em: 28 ago. 2018.

BLAIKIE, N. Designing social research: the logic of anticipation. Cambridge: Polity Press, 2009.

COSTA, D. V.; TEODOSIO, A. S. S. Desenvolvimento sustentável, consumo e cidadania: um estudo sobre a (des)articulação da comunicação de organizações da sociedade civil, do estado e das empresas. Revista de Administração Mackenzie, São Paulo, v. 12, n. 3, p. 114-145, 2011.
DELFIM NETO, A. Pensar a Alca. Revista de Administração Mackenzie, São Paulo, v. 2, n. 1, p. 11-15, 2001.

REVISTA DE ADMINISTRAÇÃO MACKENZIE - RAM. Instructions to authors. 2018a. Disponível em: <http://www.scielo.br/revistas/ram/ iinstruc.htm>. Acesso em: 27 ago. 2018.

REVISTA DE ADMINISTRAÇÃO MACKENZIE - RAM. Metrics. 2018b. Disponível em: <https://analytics.scielo.org/w/accesses/list/articles>. Acesso em: 27 ago. 2018.

RIBEIRO, K. C. S.; BRESSAN, A. A. Introdução. Revista de Administração Mackenzie, São Paulo, v. 10, n. 6, p. 2-3, 2009.

\section{Silvio Popadiuk}

Bolsa Produtividade Modalidade PQ2 entre 2009-2015 e entre 2017-2020; Pós-Doutorado na Universidade de Toronto - Faculty of Information Studies, Canadá (2004); Doutorado (1996) e Mestrado (1992) em Administração de Empresas pela FEA-USP; Bacharel em Estatística pelo Instituto de Matemática e Estatística da USP (IME-USP- 1978); Professor adjunto da Universidade Presbiteriana Mackenzie desde 1993; Componente do programa de Pós-Graduação e Administração de Empresas desde 1999; Editor-chefe da Revista de Administração Mackenzie (RAM) - Qualis CAPES B1, desde junho de 2014, São Paulo - SP, Brasil. E-mail: spopadiuk@gmail.com

\section{Vitória Batista Santos Silva}

Estudante do Mestrado Profissional em Economia e Mercados da Universidade Presbiteriana Mackenzie (UPM); Bacharel em Ciências Econômicas pela Universidade Presbiteriana Mackenzie (UPM); Assistente Técnica da Revista de Administração Mackenzie (RAM), São Paulo - SP, Brasil. E-mail: vit_batista@hotmail.com 